\title{
Climate Change and Health: Local Solutions to Local Challenges
}

\author{
Paul J. Schramm ${ }^{1} \cdot$ Munerah Ahmed $^{2} \cdot$ Hannah Siegel $^{2} \cdot$ Jamie Donatuto $^{3} \cdot$ Larry Campbell $^{3} \cdot$ Kristin Raab $^{4}$. \\ Erik Svendsen ${ }^{1}$
}

Accepted: 6 October 2020 / Published online: 28 October 2020

(C) This is a U.S. Government work and not under copyright protection in the US; foreign copyright protection may apply 2020

\begin{abstract}
Purpose of Review Climate change has direct impacts on human health, but those impacts vary widely by location. Local health impacts depend on a large number of factors including specific regional climate impacts, demographics and human vulnerabilities, and existing local adaptation capacity. There is a need to incorporate local data and concerns into climate adaptation plans and evaluate different approaches.

Recent Findings The Centers for Disease Control and Prevention (CDC) has provided funding, technical assistance, and an adaptation framework to assist localities with climate planning and activities. The differing processes with which states, cities, and tribes develop and implement adaptation plans have been observed. We outline examples of the implementation of CDC's framework and activities for local adaptation, with a focus on case studies at differing jurisdictional levels (a state, a city, and a sovereign tribe).
\end{abstract}

Summary The use of local considerations and data are important to inform climate adaptation. The adaptable implementation of CDC's framework is helping communities protect health.

Keywords Climate $\cdot$ Climate and health $\cdot$ Climate adaptation

\section{Introduction}

Climate change is a threat to human health, with impacts expected to continue in the future [1]. Heat-related illness, vector-borne diseases, food- and water-borne illness, mental health and stress-related disorders, and cardiorespiratory disease are all potential negative health outcomes from exposure to climate-related hazards [2]. The health impact and cost in

This article is part of the Topical Collection on Global Environmental Health \& Sustainability

Paul J. Schramm

pschramm@cdc.gov

1 Climate and Health Program, Centers for Disease Control and Prevention, MS S106-6, 4770 Buford Hwy, Atlanta, GA 30341, USA

2 New York City Department of Health \& Mental Hygiene, New York, NY, USA

3 Swinomish Indian Tribal Community, La Conner, WA, USA

4 Minnesota Department of Health, Saint Paul, MN, USA the United States (US) is large - one study examined ten climate-related events (ranging from wildfires to floods) in 2012, and found they resulted in an estimated 917 deaths, 20,568 hospitalizations, and 17,857 emergency department visits, with a financial burden from these health impacts between $\$ 2.7$ and $\$ 24.6$ billion [3].

Climate impacts are not distributed evenly. Regional and local effects of climate change vary widely; the Fourth National Climate Assessment details differentiation in the widespread effects of increasing greenhouse gas concentrations on the climate of ten different regions of the US [4••]. These variations necessitate that local governments plan accordingly: for example, Charleston, SC, developed adaptation approaches focused on coastal flooding and extreme weather events [5], while Maricopa County in Arizona has a climate and health strategic plan that focuses on extreme heat and drought [6]. The health effects resulting from climate change are also not distributed equally, and vary within and across regions and across timescales. Local health vulnerability is dependent on a complex variety of factors including exposures, geography, demographics, inherent sensitivities, and local adaptive capacity. Certain populations, including 
children, older adults, low-income communities, and some communities of color are at greater risk of suffering negative health impacts from climate change [7].

Many state, local, and tribal governments across the US are developing and implementing climate and health adaptation activities, including specific interventions to help individuals and communities prepare for the health effects of climate change. These adaptive efforts must be tailored to local context to be effective. An analysis of local climate impacts and vulnerabilities can ensure an effective process. Engaging a diverse set of public health stakeholders at the local level helps to inform adaptation gaps and results in more collaborative projects to build resilience $[8 \bullet, 9]$.

Despite being on the "front lines," many local jurisdictions lack adaptation capacity, and national and regional governments can help to build this capacity [10]. The Centers for Disease Control and Prevention (CDC) provides funding and technical assistance to localities to address the current and future health impacts of a changing climate. This manuscript presents CDC's framework for climate and health adaptation, and case studies from a city, state, and tribe.

\section{CDC's Climate and Health Framework and Technical Assistance}

CDC's climate and health work began in 2006, and the Climate and Health Program was formally established in 2009 with congressional funding [11]. The program is the national leader in empowering communities to protect human health from a changing climate through implementation of a three-pronged approach:

1. Building the evidence base through research and study of health impacts of climate change and effectiveness of interventions

2. Expanding capacity through provision of funding and technical support

3. Telling the story through implementation of a communication strategy

CDC developed and launched the Building Resilience Against Climate Effects (BRACE) framework to support local jurisdictions in adapting to climate change [12]. The five steps of the BRACE framework are outlined in Fig. 1, and span from an initial climate assessment to implementation and evaluation of an adaptation plan. The first step of BRACE emphasizes the importance of using local data by requiring health departments to identify the range of localized climate impacts, associated potential health outcomes, and vulnerable populations and locations within a jurisdiction. This focus on local impacts helps guide jurisdictions toward local solutions for local problems. To support implementation of the BRACE framework, CDC created a series of products, including ten BRACE technical reports, a communications toolkit, factsheets, and infographics [13].

The CDC guide on vulnerability assessment provides a suggested sequence of steps that health departments can undertake to use local data to assess health vulnerabilities associated with climate change, including identifying the area of interest and the projected change in climate exposures at the smallest possible spatial scale, identifying local risk factors (e.g., socioeconomic factors, environmental factors, infrastructure, pre-existing health conditions), and assessing the jurisdiction's adaptive capacity in terms of the system's (e.g., communities, institutions, public services) ability to reduce hazardous exposure and cope with the health consequences resulting from the exposure [14]. A technical report on intervention assessment provides guidance for local implementation of specific interventions to protect health [15••]. The BRACE framework is the only comprehensive framework for addressing the health impacts of climate change, but as part of the BRACE process, health officials can also incorporate strategies from other frameworks focusing on topics such as health equity, social vulnerability, or health evaluation.

To facilitate widespread implementation of the BRACE framework at the local scale, eighteen states and two cities are directly funded by CDC through the Climate-Ready States and Cities Initiative (CRSCI) [16]. Ten jurisdictions were originally funded beginning in 2010, and additional jurisdictions have been funded over time. A major expansion was launched in 2016 with the Climate-Ready Tribes Initiative and Climate-Ready Territories Initiative. Tribal communities have unique vulnerabilities to climate-related events. The CDC partnered with the National Indian Health Board (NIHB) to create the Climate-Ready Tribes Initiative to build on existing capacity within indigenous communities. The initiative has funded and provided direct technical assistance to ten tribes, and also supports a cohort of additional tribal professionals and partners that discuss best practices on climate and health adaptation through webinars and conference sessions. Similarly, the Climate-Ready Territories Initiative was also launched in 2016 as a partnership between CDC and the Association of State and Territorial Health Officials (ASTHO). The initiative seeks to address the highly specialized needs of island territories of the United States and has provided direct funding to three territories and direct technical assistance to all territories and freely associated states. The CRSCI was further expanded in 2019 and 2020 through the establishment of mini-grants, smaller 1-year projects administered through cooperative agreements with non-profit partners: the National Environmental Health Association, National Association of County and City Health Officials, and the Council for State and Territorial Epidemiologists. From 2010 to 2020, a total of 43 cooperative agreements to 39 jurisdictions were implemented (Fig. 2). 


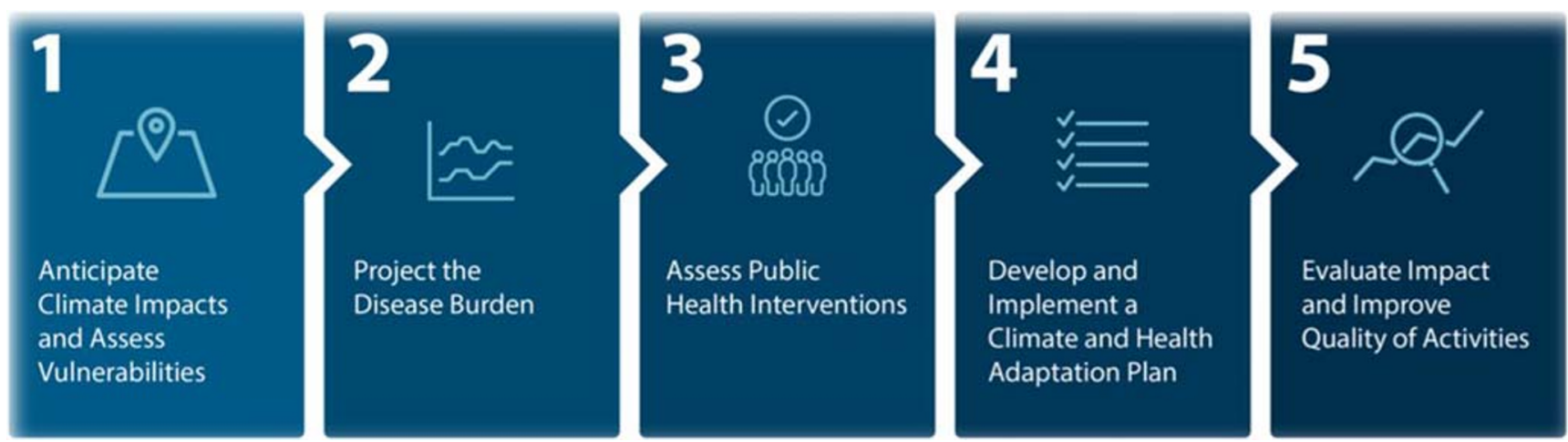

Fig. 1 The five-step BRACE framework

Small grants from CDC-funded CRSCI states to local jurisdictions have been another effective method of supporting local climate and health adaptation efforts. While not a requirement, several states receiving CDC funding have distributed competitive sub-grants to counties and cities within their states. These grants facilitate capacity building, forging partnerships with entities outside of health departments, incorporating climate change information into existing programs, and developing adaptation plans, while streamlining collaboration across multiple levels of government. Surveys of grant recipients found increases in knowledge, engagement with diverse stakeholders, and the incorporation of climate change content into existing local programs [17•].

\section{Case Studies}

Local challenges across the funded jurisdictions are highly variable, and the processes used are inherently different depending on local factors. Data on climate hazards, risks, and vulnerabilities on small geographic scales can inform effective adaptation strategies. The three case studies below outline

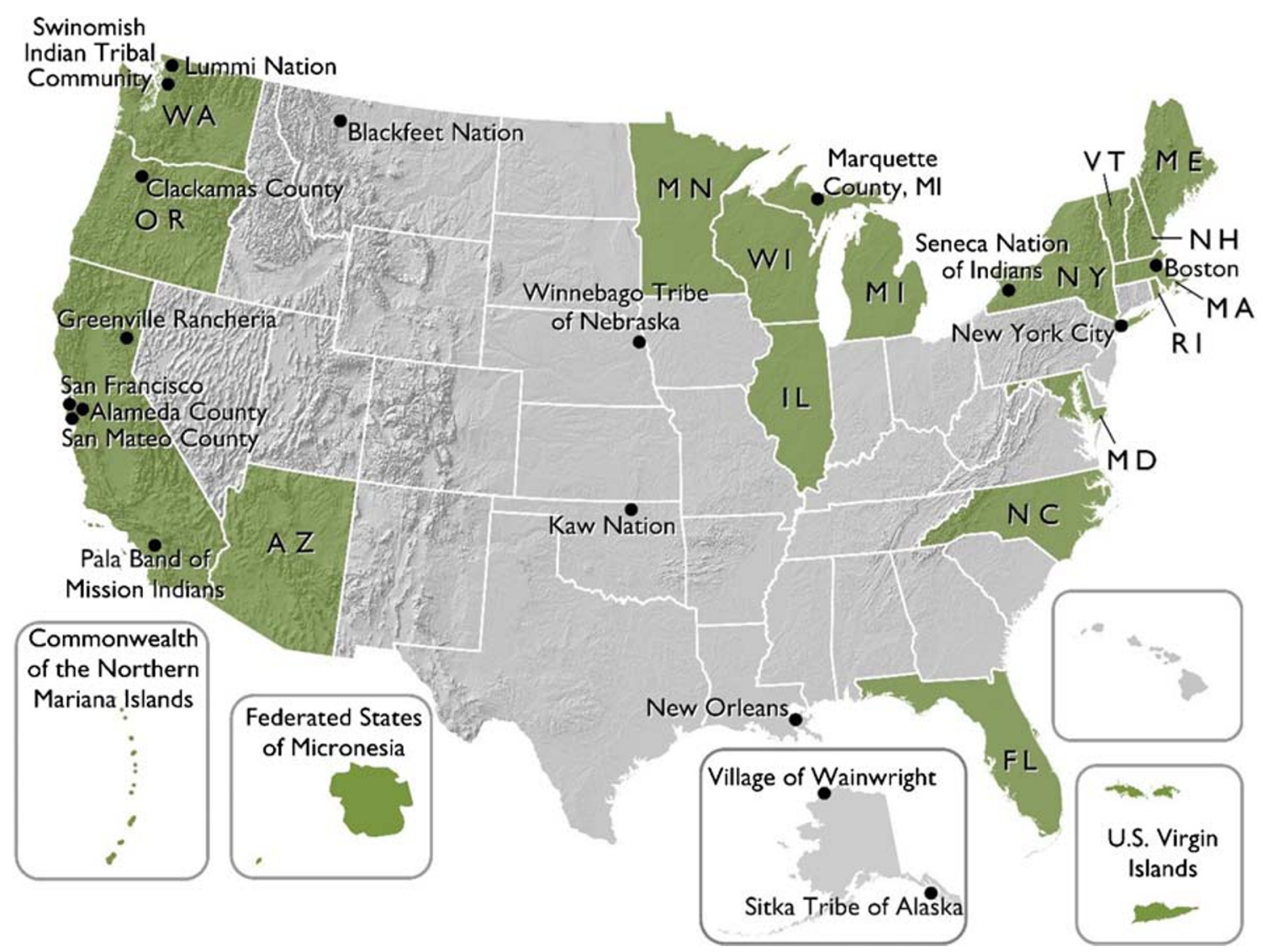

Fig. 2 All CDC climate and health grant recipients, including partner mini-grants, 2010-2020 
how a city health department, a state health department, and a tribal government have incorporated local data and considerations to guide their climate and health adaptation process.

\section{Case Study 1: Climate and Health Adaptation in a City: New York City's “Be a Buddy" Program}

Extreme weather poses serious public health risks to New York City (NYC) which climate change will increase [18-22]. Climate resilience must address both physical and social infrastructures. Social cohesion is a climate resiliency strategy that can protect communities against climate-related hazards and has numerous co-benefits [23-26]. The 1995 Chicago Heat Wave demonstrated the protective effects of social cohesion, where communities with greater social connections and trusted community institutions had fewer deaths than similar neighborhoods that had higher levels of distrust of neighbors, commercial blight, and crime [25, 26]. In 2017, as part of NYC's strategic plan to combat extreme heat, the Department of Health and Mental Hygiene (DOHMH) and Mayor's Office of Resiliency launched Be A Buddy (BAB) to bolster social cohesion as a pathway to climate resiliency [27].

$\mathrm{BAB}$ focuses on extreme heat which is, on average, the most fatal extreme weather in NYC and nationally [28]. Its relative frequency also allows for testing of interventions with applicability to other climate hazards. In NYC, most deaths occur after indoor heat exposure [18]. Heat-vulnerable persons lack air conditioning and are older, have chronic health or serious mental health conditions, misuse drugs or alcohol, or use medications affecting thermoregulation [18]. The NYC Heat Vulnerability Index visualizes neighborhood-level risk of dying from extreme heat across neighborhoods based on social and environmental characteristics [29, 30]. Predominantly non-Latino Black communities disproportionately experience more heat-related illness and death [29] due partly to structural racism which inequitably impacts access to resources and opportunities [31].

The overarching $\mathrm{BAB}$ model is to build hyperlocal networks in three heat-vulnerable neighborhoods that strengthen social connections between heat-vulnerable residents ("clients"), local volunteers, and partner community-based organizations (CBOs). Each partner CBO applies its expertise and community connections to develop and implement its $\mathrm{BAB}$ network: an intergenerational network where youth volunteers check on clients and build job readiness (Brooklyn Community Services in Brownsville, Brooklyn); a network using arts and culture to teach environmental justice (The POINT Community Development Corporation in Hunts Point, Bronx); and an older adult peer-to-peer network (Union Settlement in East Harlem, Manhattan).

Participants are recruited through referrals, word-of-mouth, flyers, and other channels. During extreme heat and other extreme weather, $\mathrm{CBO}$ staff and volunteers alert clients about the weather, assess their safety, and assist if needed. For example, a volunteer may help a client without a working air conditioner find the nearest cooling center and transportation there. During non-emergencies, CBOs promote events such as communal meals, dance classes, or block parties to foster social connections.

The BAB networks currently include 1020 clients and 39 volunteers. Approximately $77 \%$ of clients are ages 55 years or older. The majority are Black and Latina women with multiple chronic medical conditions. Approximately $75 \%$ live in subsidized or public housing. From May 2018 to February 2020, the CBOs conducted or participated in over 500 engagement events, and activated 11 times for extreme heat, winter emergencies, and power outages. Factors that impact activation reach include advanced forecast of weather events, volunteer activations on weekdays versus weekends, and additional staff as networks expanded.

Qualitative findings include:

- Cultivate relationships between residents slowly and naturally to build trust and familiarity.

- Build routine (e.g., staff/volunteers at the same place and time).

- Use face-to-face interactions in community spaces, phone calls, and social media. Clients do not like unknown numbers or home check-ins.

- Communicate events and emergencies through word-ofmouth via community gatekeepers. For example, "La Doña Network" in Hunts Points are long-standing, wellknown residents who serve as conduits to community and government services. Informal gathering spaces, such as bodegas, can also amplify messages.

- Be agile. BAB has great transferability to many public health concerns. For example, the CBOs voluntarily activated their BAB networks for COVID-19, conducting over 4000 virtual check-ins with a $73 \%$ reach rate. Additionally, CBOs are providing critical situational awareness to DOHMH.

$\mathrm{BAB}$ can provide a lifeline during extreme heat and other extreme weather [32]. These and forthcoming findings can illuminate how, as part of larger comprehensive heat action plans, BAB could be expanded to build quality connections between local clients, volunteers, and other organizations in NYC and elsewhere.

\section{Case Study 2: Climate and Health Adaptation in an Indigenous Community: Swinomish Indian Tribal Community's Adaptation of the BRACE Framework}

The Swinomish Indian Tribal Community (Swinomish) is a Coast Salish nation located in present day Washington State. With funding in part from CDC through the Climate-Ready 
Tribes Initiative in partnership with the National Indian Health Board, the Swinomish have indigenized the CDC's BRACE framework to account for specific local needs. The process involved adapting and adjusting the BRACE framework to incorporate Swinomish concepts of health - specifically, local understanding of indigenous values-based data collection, analysis, and decision-making. This adaptation of BRACE enhanced usability and applicability to the needs of the Swinomish community by considering cultural, social, mental, and environmental definitions of health [33•].

The Swinomish have a number of practices that can be affected by a changing climate, including traditional hunting and fishing practices. Harvesting, preparing, and using traditional foods and resources is part of the social and cultural fabric in the community. The local concept of human health defines an overall healthy community as determined through generations of knowledge and practices developed through connection to lands and waters. The interrelated relationships between nature, humans, non-human beings, natural resources, and the spiritual realm all combine as facets important to determining health. The indigenization of CDC's BRACE framework incorporates this complex definition of health, allowing BRACE to be accurately applied to the local context by reflecting non-physiological health priorities that are often left out of climate and health assessments when conducted by a state or local health department. The use of the indigenized framework also facilitated community discussions to further refine health priorities and key adaptation actions.

When implementing a locally contextualized version of the BRACE framework, the Swinomish first meaningfully engaged in "values-based" decision-making to design climate and health solutions that were responsive to community priorities, and in turn more likely to be supported and implemented $[33 \cdot, 34]$. This provided opportunities to discuss and refine community perceptions of climate impacts, which were then incorporated into the decision-making process [35]. The resulting product was a set of Indigenous Health Indicators (IHI) that incorporate community-held values of health: community connection, natural resources security, cultural use and practices, education, self-determination, and resilience [36]. The effort also used traditional climate projections to anticipate impacts on key traditional foods and ecosystems, and presented this information to community participants to rank the importance of priority habitat locations. Adaptation strategies were developed by Tribal staff that incorporated the IHI and community priority input, and these strategies were included into the Swinomish Climate Action Plan. Funding from the Robert Wood Johnson Foundation allowed for an evaluation of the effectiveness of the modified BRACE framework, which is currently in progress.

While the work of the Swinomish may be relevant to some other indigenous communities, and even to state/local health departments and non-indigenous people, it is important to note that vast differences exist between indigenous communities. The indigenized BRACE framework developed by the Swinomish should not be assumed to be relevant to other tribes, but it certainly provides a methodology and potentially useful products and outcomes that can be incorporated into future work by other communities. For example, the concept that health is not merely an individual biophysical measurement, but rather that health is determined at community and familial scales, may be broadly applicable to other indigenous communities [36, 37].

\section{Case Study 3: Climate and Health Adaptation in a State: Vulnerability Assessments Inform Resiliency Strategies in Minnesota}

The Minnesota Department of Health's Minnesota Climate and Health Program (CH Program) focuses on protecting public health from climate change by providing education and research on the health impacts of climate change and building capacity of local governments and others to implement climate resiliency solutions through the use of evidenced-based resources and tools. The $\mathrm{CH}$ Program has placed particular emphasis on development of vulnerability assessments tailored to Minnesota's climate drivers, i.e., more frequent and severe precipitation events and warming temperatures. Vulnerability assessments assist local jurisdictions in identifying the places and people most at risk of negative health outcomes from climate hazards. Armed with this information, local public health practitioners, emergency managers, planners, and others can use this information to craft resiliency strategies that meet their jurisdiction's unique vulnerabilities and assets.

Severe rainfall events, defined as 3-in. rainfalls, have increased $65 \%$ in Minnesota [38]. These types of events increase the likelihood of flooding and possible concomitant contamination of drinking water. Contaminated drinking water can expose people to a variety of harmful pollutants and pathogens, putting them at risk for a number of health issues. Private well water tends to have a greater chance of contamination due to the fact that well owners are responsible for testing, treating, and protecting their well water, unlike public water suppliers that are regulated by the Safe Drinking Water Act. Approximately 1.2 million people (about $21 \%$ of Minnesotans) obtain their drinking water from a private well.

To better understand the health risks related to flooding and private well water contamination, the $\mathrm{CH}$ Program completed a vulnerability assessment of future flooding impacts for populations on private wells based on a number of characteristics, including estimated future extreme precipitation and location of a private well in a floodplain. The data suggested that by mid-century (2050-2074), 80\% of Minnesota counties will experience June extreme rainfall levels historically associated with disaster-level flooding, and over 22,000 private wells 
could be more susceptible to flooding due to their location within a floodplain [39]. The vulnerability assessment highlighted the possible future level of flooding that Minnesota needs to prepare for, as well as the number of private wells that could be severely impacted. MDH used the assessment to elevate the issue of flood-sensitive wells in Minnesota and improve well safety messaging to well owners to increase the frequency of testing and improve well head protection during extreme precipitation events.

Another vulnerability assessment created by the $\mathrm{CH}$ Program, with the assistance of U-Spatial at the University of Minnesota, was the online Heat Vulnerability in Minnesota Tool. The tool provides local jurisdictions throughout Minnesota easy access to important information useful for planning for extreme heat events. The tool contains two main components of vulnerability assessments, i.e., exposure data and sensitivity data. The exposure data helps local jurisdictions understand the degree to which their area is exposed to extreme heat, as measured by number of excessive heat warnings and heat advisories and projected cooling degree days (to indicate future potential heat exposure). The sensitivity data encompasses a range of factors, including demographic variables, socioeconomic variables, and pre-existing health issues that influence the ability of a community to withstand extreme heat. The tool has been used by counties to raise awareness of the emerging issue of extreme heat and inform local jurisdictional risk assessment related to emergency preparedness. To learn more about the climate and health work at $\mathrm{MDH}$, visit the CH Program's website [40].

\section{Conclusions}

Climate change has a significant impact on health in the United States, and adaptation activities are needed to address this growing threat. Because of large geographic variations in climate impacts, and differences in demographics and vulnerability, jurisdictions must plan at a local scale. Utilization of local data and expertise can drive effective programs tailored to specific needs. The process avoids a top-down approach, instead encouraging cooperation with grassroots level involvement and CDC facilitation including the use of the flexible framework. Delivery of climate and health guidance by the federal government is difficult, as general guidance would not be applicable to many areas. To address this problem, CDC created a unique adaptable framework, BRACE. This framework has been implemented in a wide variety of ways, as illustrated by the three case studies in this manuscript.

A one-size-fits-all funding model would also not work for climate and health adaptation. Grants to only cities/counties would neglect the large-scale planning and data analysis that can be provided by state governments, while funding to only states would not fully address local needs and impacts. CDC funds jurisdictions at varying scales, ranging from small rural counties to large populous states and sovereign tribal nations. Grant amounts have varied from as little as $\$ 5000$ for 1-year climate and health communication projects to over $\$ 200,000$ per year for multi-year cooperative agreements to fully implement BRACE. This approach has resulted in a broad array of projects tackling a variety of complex local climate impacts.

A number of barriers exist that can prevent the development of local solutions. Localities can face a dearth of needed data, or lack the capacity or expertise to apply data. Local surveillance systems, climate data downscaled to the local level, and ability to interpret that data, are necessary for developing preventive climate-health policy responses [41]. One study conducted stakeholder interviews in US cities and found that a lack of information on health impacts at the city scale limited the ability for local experts and policy makers to develop well-informed adaptation plans [42]. The BRACE framework requires staff (and thus funding) to implement, which can be challenging for health departments with limited resources.

Lack of adequate collaborations and partnerships can also hinder adaptation work. Climate change adaptation is inherently cross-disciplinary and cross-sectoral. Localities often require technical partners to assist with downscaling data to the locally relevant level [43]. In metropolitan regions, institutional fragmentation in governance and lack of collaboration across local jurisdictions can hinder the incorporation of health concerns into broader climate planning [42]. Many public health interventions require health departments to engage with entities in other sectors, such as sustainability offices, transportation authorities, and urban planners. To address this need, CDC created guidance for health departments to aid cross-sectoral projects [44]. This guidance, as well as the full suite of guidance available from $\mathrm{CDC}$, enables local communities to engage stakeholders and prepare for the specific local climate impacts on health.

CDC's Climate and Health Program has had a significant impact on the field of climate and health adaptation. Ongoing evaluation will help to determine the health and economic benefits of the programs implements by CDC's grant recipients. Preliminary evidence indicates that localities funded by the Climate-Ready States and Cities Initiative are more likely to have developed climate adaptation plans and assessed appropriate interventions. Demonstrating direct health impacts, such as a reduction in mortality, is difficult given the scope of the interventions, the length of time they have been implemented, and the complex variety of factors that affect health outcomes. CDC and state, local, and tribal health departments continue to collect data on health outcomes as well as intermediate outcomes (such as change in knowledge or behavior) to assess effectiveness of specific interventions.

Lessons learned from CDC's work have already been applied in other contexts. Health Canada's HealthADAPT 
program, which provides funding and assistance to ten health authorities to support their climate change and health efforts, was based on CDC's Climate-Ready States and Cities Initiative $[45 \cdot, 46]$. Strong national coordination and effective institutions can bolster local adaptive capacity [47]. CDC's efforts have strengthened the capacity of local public health agencies and helped to integrate health more fully into broader climate planning [43]. With a continued focus on informing and supporting local efforts, climate capacity in the US will continue growing.

Acknowledgments The authors would like to acknowledge Emmanuelle Hines, Josephine Malilay, Nancy Jeffery, and Fernando Tirado for their contributions to this document.

\section{Compliance with Ethical Standards}

Human and Animal Rights and Informed Consent This article does not contain any studies with human or animal subjects performed by any of the authors.

Disclaimer The findings and conclusions in this report are those of the author(s) and do not necessarily represent the official position of the Centers for Disease Control and Prevention or any state, local, or tribal jurisdiction.

\section{References}

Papers of particular interest, published recently, have been highlighted as:

- Of importance

•. Of major importance

1. Crimmins A, Balbus J, Gamble JL, Beard CB, Bell JE, Dodgen D, et al. The impacts of climate change on human health in the United States: a scientific assessment [Internet]. U.S. Global Change Research Program; 2016 [cited 2020 May 1]. Available from: https://health2016.globalchange.gov/downloads.

2. Centers for Disease Control and Prevention (CDC) Climate and Health Program. Climate effects on health [Internet]. 2019 [cited 2020 Apr 15]. Available from: https://www.cdc.gov/ climateandhealth/effects/default.htm.

3. Limaye VS, Max W, Constible J, Knowlton K. Estimating the health-related costs of 10 climate-sensitive U.S. events during 2012. GeoHealth. 2019;3(9):245-65.

4.• Reidmiller DR, Avery CW, Easterling DR, Kunkel KE, Lewis KLM, Maycock TK, et al. Impacts, risks, and adaptation in the United States: the Fourth National Climate Assessment, volume II [Internet]. U.S. Global Change Research Program; 2018 [cited 2020 May 1]. Available from: https://nca2018.globalchange.gov/. Seminal report on climate impacts in the United States, including human health impacts.

5. Runkle J, Svendsen ER, Hamann M, Kwok RK, Pearce J. Population health adaptation approaches to the increasing severity and frequency of weather-related disasters resulting from our changing climate: a literature review and application to Charleston, South Carolina. Curr Environ Health Rep. 2018;5(4): 439-52.
6. Maricopa County Department of Public Health. Climate and health strategic plan for Maricopa County 2016-2021 [Internet]. 2018 [cited 2020 May 1]. Available from: https://www.maricopa.gov/ DocumentCenter/View/38688/Climate-and-Health-Strategic-Plan2016-2021-PDF.

7. Gamble JL, Balbus J, Berger M, Bouye K, Campbell V, Chief K, et al. Ch. 9: Populations of concern. The impacts of climate change on human health in the United States: a scientific assessment [Internet]. U.S. Global Change Research Program; 2016 [cited 2020 May 1]. Available from: https://health2016.globalchange. gov/downloads\#populations-of-concern.

8. Austhof E, Berisha V, McMahan B, Owen G, Keith L, Roach M, et al. Participation and engagement of public health stakeholders in climate and health adaptation. Atmosphere. 2020;11(3):265 Summary of scientist-public health stakeholder collaboratives in addressing the public health impacts of climate-sensitive hazards.

9. Eidson M, Clancy KA, Birkhead GS. Public health climate change adaptation planning using stakeholder feedback. J Public Health Manag Pract. 2016;22(1):E11-9.

10. Austin SE, Ford JD, Berrang-Ford L, Biesbroek R, Ross NA. Enabling local public health adaptation to climate change. Soc Sci Med. 2019;220:236-44.

11. Hess JJ, Marinucci G, Schramm PJ, Manangan A, Luber G. Management of climate change adaptation at the United States Centers for Disease Control and Prevention. In: Pinkerton KE, Rom WN, editors. Global climate change and public health. New York: Springer; 2013. p. 341-60. [cited 2020 May 1]. Available from: http://link.springer.com/10.1007/978-1-4614-8417-2 20.

12. Marinucci GD, Luber G, Uejio CK, Saha S, Hess JJ. Building resilience against climate effects - a novel framework to facilitate climate readiness in public health agencies. Int J Environ Res Public Health. 2014;11(6):6433-58.

13. Centers for Disease Control and Prevention (CDC) Climate and Health Program. Guidance and trainings [Internet]. 2020 [cited 2020 Apr 1]. Available from: https://www.cdc.gov/ climateandhealth/guidance.htm.

14. Manangan AP, Uejio CK, Saha S, Schramm PJ, Marinucci GD, Hess J, et al. Assessing health vulnerability to climate change: a guide for health departments [Internet]. Climate and Health Program, Centers for Disease Control and Prevention (CDC); 2014. Available from: https://www.cdc.gov/climateandhealth/ pubs/assessinghealthvulnerabilitytoclimatechange.pdf

15.• Anderson H, Brown C, Cameron LL, Christenson M, Conlon KC, Dorevitch S, et al. Climate and health intervention assessment: evidence on public health interventions to prevent the negative health effects of climate change: Centers for Disease Control and Prevention; 2017. p. 96. Comprehensive literature review of the effectiveness of specific adaptations and interventions to protect health from a changing climate.

16. Centers for Disease Control and Prevention (CDC) Climate and Health Program. Climate-ready tates \& cities initiative grantees [Internet]. 2019 [cited 2020 Mar 15]. Available from: https:// www.cdc.gov/climateandhealth/crsci grantees.htm.

17. Grossman E, Hathaway M, Bush KF, Cahillane M, English DQ, Holmes T, et al. Minigrants to local health departments: an opportunity to promote climate change preparedness. J Public Health Manag Pract. 2019;25(2):113-20 Evaluation of grants from states to cities and counties to build local capacity and crossgovernmental collaboration.

18. Centers for Disease Control and Prevention. Heat illness and deaths - New York City, 2000-2011. Morb Mortal Wkly Rep. 2013;62(31):617-21.

19. Lane K, Charles-Guzman K, Wheeler K, Abid Z, Graber N, Matte T. Health effects of coastal storms and flooding in urban areas: a review and vulnerability assessment. J Environ Public Health. 
2013;2013:e913064 Hindawi; [cited 2020 May 1]. Available from: https://www.hindawi.com/journals/jeph/2013/913064/.

20. Dominianni C, Lane K, Johnson S, Ito K, Matte T. Health impacts of citywide and localized power outages in New York City. Environ Health Perspect. 2018;126(6):067003.

21. The City Of New York. Hurricane sandy after action: report and recommendations to Mayor Michael R. Bloomberg [Internet]. New York City, New York; 2013 [cited 2020 May 1]. Available from: https://www1.nyc.gov/assets/housingrecovery/downloads/pdf/ 2017/sandy aar 5-2-13.pdf.

22. New York City Panel on Climate Change 2019 Report Executive Summary. Ann N Y Acad Sci. 2019;1439(1):11-21.

23. Chuang Y-C, Chuang K-Y, Yang T-H. Social cohesion matters in health. Int J Equity Health. 2013;12(1):87.

24. Boxall A, Short SD. Political economy and population health: is Australia exceptional? Aust N Z Health Policy. 2006;3(1):6.

25. Klinenberg E. Heat wave: a social autopsy of disaster in Chicago: University of Chicago Press; 2002. p. 342.

26. Klinenberg E. How can cities be "climate-proofed"? The New Yorker [Internet]. 2012 [cited 2020 May 1]; Available from: https://www.newyorker.com/magazine/2013/01/07/adaptationeric-klinenberg.

27. The City Of New York. Cool neighborhoods NYC: a comprehensive approach to keep communities safe in extreme heat. New York City, New York; 2017 p. 44.

28. National Weather Service. Office of Climate, Water, and Weather Services. Natural Hazard Statistics. [Internet]. NOAA National Weather Service Weather Related Fatality and Injury Statistics. NOAA's National Weather Service; 2018 [cited 2020 May 1]. Available from: https://www.weather.gov/hazstat/.

29. Madrigano J, Ito K, Johnson S, Kinney PL, Matte T. A case-only study of vulnerability to heat wave-related mortality in New York City (2000-2011). Environ Health Perspect. 2015;123(7):672-8.

30. New York City Department of Health and Mental Hygiene. Heat vulnerability index [Internet]. NYC Environment and Health Data Portal. 2020 [cited 2020 Jun 5]. Available from: http://a816dohbesp.nyc.gov/IndicatorPublic/VisualizationData.aspx?id= 2191,719b87,107,Map,Score,2018

31. Lawrence K, Sutton S, Kubisch A, Susi G, Fulbright-Anderson K. Aspen Institute roundtable on community change: structural racism and community building. The Aspen Institute: Washington, D.C; 2004.

32. New York City Department of Health and Mental Hygiene. American Community Survey: estimated number of people aged 65 and older living alone [Internet]. NYC Environment and Health Data Portal. 2020 [cited 2020 Jun 5]. Available from: http://a816dohbesp.nyc.gov/IndicatorPublic/VisualizationData.aspx?id= 2146,4466a0,109,Summarize.

33. Donatuto J, Campbell L, Trousdale W. The "value" of valuesdriven data in identifying indigenous health and climate change priorities. Clim Chang. 2020;158(2):161-80 Novel process for utilizing values-driven data in tribal climate and health adaptation activities.

34. Gregory R, Easterling D, Kaechele N, Trousdale W. Values-based measures of impacts to indigenous health: perspective. Risk Anal. 2016;36(8):1581-8
35. Pidgeon N, Fischhoff B. The role of social and decision sciences in communicating uncertain climate risks. Nat Clim Chang. 2011;1(1):35-41.

36. Donatuto J, Campbell L, Gregory R. Developing responsive indicators of indigenous community health. Int J Environ Res Public Health. 2016;13(9):899.

37. Donatuto JL, Satterfield TA, Gregory R. Poisoning the body to nourish the soul: prioritising health risks and impacts in a Native American community. Health Risk Soc. 2011;13(2):103-27.

38. Minnesota Interagency Climate Adaptation Team. Building resiliency to extreme precipitation in Minnesota: ICAT Workgroup \#1 White Paper [Internet]. 2018 [cited 2020 May 1]. Available from: https://bwsr.state.mn.us/sites/default/files/2018-12/Building Resiliency to Extreme Precipitation in Minnesota-ICAT White_Paper\% $282 \% 29 . p \overline{d f}$.

39. Hoppe BO, Raab KK, Blumenfeld KA, Lundy J. Vulnerability assessment of future flood impacts for populations on private wells: utilizing climate projection data for public health adaptation planning. Clim Chang. 2018;148(4):533-46.

40. Minnesota Department of Health. Climate and Health - Minnesota Department of Health [Internet]. 2019 [cited 2020 May 1]. Available from: https:/www.health.state.mn.us/communities/ environment/climate/index.html.

41. Fox M, Zuidema C, Bauman B, Burke T, Sheehan M. Integrating public health into climate change policy and planning: state of practice update. Int J Environ Res Public Health. 2019;16(18):3232.

42. Shimamoto MM, McCormick S. The role of health in urban climate adaptation: an analysis of six U.S. cities. Wea Climate Soc. 2017;9(4):777-85.

43. Sheehan MC, Fox MA, Kaye C, Resnick B. Integrating health into local climate response: lessons from the U.S. CDC climate-ready states and cities initiative. Environ Health Perspect. 2017;125(9): 094501.

44. Centers for Disease Control and Prevention (CDC) Climate and Health Program. Climate and health: a guide for cross-sector collaboration [Internet]. Centers for Disease Control and Prevention; 2019 p. 49. Available from: https://www.cdc.gov/climateandhealth/ docs/CrossSectorClimateandHealth.pdf.

45. Berry P, Enright PM, Shumake-Guillemot J, Villalobos Prats E, Campbell-Lendrum D. Assessing health vulnerabilities and adaptation to climate change: a review of international progress. Int $\mathrm{J}$ Environ Res Public Health. 2018;15(12):2626 Description of global activities to assess climate and health vulnerabilities.

46. Health Canada. HealthADAPT [Internet]. 2019 [cited 2020 May 1]. Available from: https://www.canada.ca/en/health-canada/ programs/health-adapt.html.

47. Ebi KL. Mechanisms, policies, and tools to promote health equity and effective governance of the health risks of climate change. $\mathrm{J}$ Public Health Policy. 2020;41(1):11-3.

Publisher's Note Springer Nature remains neutral with regard to jurisdictional claims in published maps and institutional affiliations. 